\title{
Usefulness of Bioelectric Impedance and Skinfold Measurements in Predicting Fat-Free Mass Derived from Total Body Potassium in Children ${ }^{1}$
}

\author{
F. SCHAEFER, M. GEORGI, A. ZIEGER, AND K. SCHÄRER \\ University Children's Hospital, Heidelherg, Germany' [F.S., M.G., K.S.J, and Nuclear Research Centre, \\ Karlsruhe, Germany [A.Z.]
}

\begin{abstract}
Despite the increasing use of tetrapolar whole-body bioelectric impedance (BI) analysis in the assessment of body composition, its usefulness in estimating fat-free mass (FFM) has not been evaluated in comparison with conventional skinfold anthropometry in children. We therefore compared 1 ) the intraobserver and interobserver reproducibility of $B I$ and skinfold measurements and the derived FFM estimates, and 2) the predictability of FFM as calculated from measurements of total body potassium (TBK) using ${ }^{40} \mathrm{~K}$ spectrometry by equations based on either BI or skinfold measurements in 112 healthy children, adolescents, and young adults aged 3.9 to $19.3 \mathrm{y}$. $\mathrm{A}$ bestfitting equation to predict TBK-derived FFM from BI and other potential independent predictors was developed and cross validated in two randomly selected subgroups of the study population by stepwise multiple regression analysis. Although the technical error associated with BI measurements was much smaller than that of skinfold measurements, the reproducibility of BI-derived FFM estimates (intraobserver coefficient of variation $[\mathrm{CV}], 0.39 \%$; interobserver $\mathrm{CV}, 1.23 \%$ ) was only slightly better than that of FFM estimates obtained by use of weight and two skinfold measurements $(0.62 \%$ and $1.39 \%$, respectively). The cross validation procedure yielded the following best-fitting prediction equation: FFM $=\mathbf{0 . 6 5}$. (height $^{2} /$ impedance $)_{+}+$ $0.68 \cdot$ age $+0.15\left(R^{2}=0.975\right.$, root mean square error $=$ $1.98 \mathrm{~kg}, \mathrm{CV}=5.8 \%, 95 \%$ limits of agreement $=-11.1 \%$ to $+12.4 \%$ ). Conventional anthropometry, using published equations to estimate FFM from skinfolds, slightly overestimated TBK-derived FFM, but predicted FFMI with precision similar to the best-fitting equation involving BI. Previously published FFM equations incorporating BI predicted TBK-derived FFM with variable predictive precision and accuracy. We conclude that BI analysis provides an alternative technique to assess FFM in children. At least within the range of normal body composition, its predictive power is similar to that of established skinfold techniques. (Pediatr Res 35: 617-624, 1994)
\end{abstract}

Abbreviations

FFM, fat-free mass

BI, bioelectric impedance

$R I$, resistance index

Received April 15, 1993; accepted December 16, 1993.

Correspondence and reprint requests: Dr. Franz Schaefer. Division of Pediatric Nephrology, University Children’s Hospital, Im Neuenheimer Feld 150, D-69120 Heidelberg, Germany.

Supported in part by Deutsche Forschungsgemeinschaft grants Scha 169/5-1 and Scha $477 / 6-1$.

The results of this study were presented in part at the Annual Meeting of the European Society for Pediatric Research, Vienna, 1990, and at the Annual Meeting of the Society for Pediatric Research. New Orleans, 1991.
TBK, total body potassium $\mathrm{CV}$, coefficient of variation RMSE, root mean square error

Within the past few years, BI analysis has gained wide use in the assessment of body composition. The method appears particularly suitable for use in children, because the measurements are fast, noninvasive, painless, and require little subject cooperation. The BI technique is based on the difference in specific resistance to an electrical current between aqueous and nonaqueous compartments within the body. Validation studies have shown the accuracy and precision of the technique to be at least comparable with conventional anthropometric methods such as skinfold thickness measurements in both adults and children (1-4).

The few studies performed so far in children suggest that the changing proportions of body fluid compartments during childhood may require the use of specific pediatric prediction equations (4-7). However, the validation methods used so far are difficult to apply in smaller children or rely on a number of unverifiable assumptions. Densitometric underwater weighing and respirometric assessment of residual lung volume require full subject cooperation. In addition, the specific density of the FFM seems to change during childhood; variable-density FFM models have been applied but are hypothetical $(4,8)$. Isotope dilution studies using labeled water tend to systematically overestimate total body water (9). In addition, estimation of FFM from total body water requires an assumption regarding the hydration of the FFM, which is not constant during childhood $(10,11)$. These limitations have precluded major validation studies in younger children and indicate a need for caution in the interpretation and generalization of the studies performed so far.

${ }^{40} \mathrm{~K}$ spectrometry provides a very accurate, noninvasive means of estimating body cell mass (12). Although changes in the relationship between intracellular and extracellular compartments and in the relative contributions of different tissues to body mass during childhood complicate its use in children (10), prediction equations of FFM from TBK have been developed that at least partly correct for such changes (13). Although applicable at all ages including infancy $(14,15)$, this technique has not yet been applied to validating BI analysis in children. In the present study, we had the opportunity to assess the usefulness of $\mathrm{BI}$ for the assessment of FFM in comparison with conventional skinfold anthropometry using ${ }^{40} \mathrm{~K}$ spectrometry as reference standard in a large cohort of healthy children, one third of which were younger than $10 \mathrm{y}$. A best-fitting prediction equation was derived, and its predictive precision and accuracy compared with other prediction formulas was validated by densitometry, isotope dilution, or both. 


\section{SUBJECTS AND METHODS}

Subjects. One hundred twelve healthy boys and girls living in the cities of Heidelberg and Karlsruhe, Germany volunteered for the study. The basic and anthropometric characteristics of the study population are given in Table 1 . The parents of each child or the adult subjects themselves gave written informed consent after being thoroughly briefed about the study's purposes and procedures. On the day of the study, the children were instructed to eat their usual breakfast but nothing thereafter. The studies were conducted between 1030 and $1200 \mathrm{~h}$.

To assess the reproducibility of the different anthropometric methods used, a separate study was performed in a subset of children aged 5-15 y. For assessment of interobserver variability, three observers made complete sets of anthropometric measurements in nine children. Intraobserver variability was assessed in two observers, each of whom obtained five measurement series in four children. The sequence of observer-subject combinations was randomized to minimize data memorizing.

Anthropometry. All measurements were performed by two trained observers according to standard techniques (16). Standing height was measured to the nearest $0.1 \mathrm{~cm}$ with a portable Harpenden stadiometer (Holtain Ltd, Crosswell, Crymych, Dyfed, UK). Weight was determined on a digital scale (SECA, Hamburg, Germany) with a precision of $0.1 \mathrm{~kg}$. Skinfold thicknesses were determined to the nearest $0.2 \mathrm{~mm}$ at the left biceps, triceps, subscapular, and suprailiac sites with a Holtain skinfold caliper calibrated to exert a constant pressure of $10 \mathrm{~g} / \mathrm{mm}^{2}$ (Holtain Ltd). The stage of sexual maturation was assessed according to Tanner (17). Patients were regarded as pubertal if they had reached at least breast/genital stage II and pubic hair stage II.

FFM was calculated as the difference between weight and body fat determined by 1) age- and sex-specific formulas involving weight and the log-transformed sum of the biceps, triceps, subscapular, and suprailiac skinfolds for subjects aged $<12.0,12.0$ to 15.9 , and $\geq 16.0$ y $(18-20)$ that are based on the assumption of a constant density of the FFM; and 2) age- and sex-specific equations incorporating the sum of the triceps and subscapular skinfolds, validated with a multiple-component model assuming variable density of the FFM during childhood (21).

${ }^{40} \mathrm{~K}$ spectrometry. TBK was measured in a whole-body potassium counter comprising four thallium-activated sodium-iodide crystal scintillation detectors situated at the Nuclear Research Centre, Karlsruhe. The CV for repeated measurements with this device is $<3.5 \%$ for individuals between 10 and $100 \mathrm{~kg}$ of body weight.

FFM was estimated from TBK according to Burmeister (13) by the following formula:

$$
\mathrm{FFM}=0.0119 \mathrm{TBK}+6.04 \cdot \mathrm{BSA}
$$

where TBK is the total body potassium in grams, assuming a constant fraction of $0.012 \%$ of ${ }^{40} \mathrm{~K}$ in TBK, and BSA is the body surface area. According to Burmeister, FFM is composed of the body cell mass containing a constant equivalent of $92.5 \mathrm{mEq}$ of potassium $/ \mathrm{kg}$, the extracellular solid mass (approximately $10 \%$ of the cellular mass), and the extracellular fluid, which, on the basis of measurements of thiosulfate space, is a linear function of BSA (22).

To cross-check this model with other methods of estimating FFM from TBK in childhood and adolescence, FFM was also calculated on the basis of the age- and sex-specific TBK:FFM ratio equations provided by Forbes (23) and the tables published by Lohman (24) based on studies by Fomon et al. (25) and Haschke (26).

BI analysis. Tetrapolar whole-body BI was measured with a body composition analyzer (Holtain Ltd) using an alternating electrical current of $0.8 \mathrm{~mA}$ and $50 \mathrm{kHz}$. The measurements were standardized according to the procedural guidelines of Lukaski ct al. (27). The electrodes were placed at defined positions on the right wrist and ankle. Care was taken that the distance between the electrodes was at least $3 \mathrm{~cm}$. The mean of three sequential readings was used as the measurement value.

In the subjects in whom measurement reliability was assessed, new electrodes were placed before each reading.

Statistical analy'ses. In the reliability studies, measurement variability of each anthropometric technique was expressed as the technical error of measurement

$$
\sigma_{\text {meas }}=\sqrt{\sum \mathrm{d}_{\mathrm{xy}}^{2} / 2 \mathrm{~N}}
$$

where $d_{x y}=$ the differences between occasions (16). The CV was defined as

$$
\mathrm{CV}=\sigma_{\text {meas }} / \mathrm{X}
$$

where $\mathrm{X}$ is the overall mean of the measurements.

Intraobserver $\sigma_{\text {meas }}$ and $\mathrm{CV}$ were calculated for each observer from all pairs of measurements in all subjects, and mean $\sigma_{\text {meas }}$ and $C V$ values were calculated for the five observers. Interobserver $\sigma_{\text {meas }}$ and $\mathrm{CV}$ were estimated in each subject from all pairs of first measurements by the different observers and averaged over all subjects.

Table 1. Basic and anthropometric characteristics of the two cross-validation groups*

\begin{tabular}{lccc}
\hline & Group A & Group B & All subjects \\
\hline$n$ & 57 & 55 & 112 \\
Boys/girls & $30 / 27$ & $29 / 26$ & $59 / 53$ \\
Prepubertal/pubertal & $23 / 34$ & $26 / 29$ & $49 / 63$ \\
Age $(\mathrm{y})$ & $12.0 \pm 3.7(5.3-19.3)$ & $11.7 \pm 3.7(3.9-18.5)$ & $11.8 \pm 3.7(3.9-19.3)$ \\
Height $(\mathrm{cm})$ & $150.9 \pm 17.8(114.0-186.9)$ & $149.5 \pm 21.6(103.0-187.6)$ & $150.2 \pm 19.7(103.0-187.6)$ \\
Weight & $42.8 \pm 15.1(18.9-75.2)$ & $42.8 \pm 18.1(17.8-80.0)$ & $42.8 \pm 16.6(17.8-80.0)$ \\
Body surface area $\left(\mathrm{m}^{2}\right)$ & $1.34 \pm 0.31(0.79-2.00)$ & $1.33 \pm 0.38(0.71-2.02)$ & $1.34 \pm 0.34(0.71-2.02)$ \\
Triceps skinfold $(\mathrm{mm})$ & $10.4 \pm 4.7(3.8-23.2)$ & $10.4 \pm 4.2(5.0-23.2)$ & $10.4 \pm 4.4(3.8-23.2)$ \\
Biceps skinfold (mm) & $6.7 \pm 3.7(2.9-21.0)$ & $6.5 \pm 2.8(3.0-15.6)$ & $6.6 \pm 3.3(2.9-21.0)$ \\
Subscapular skinfold $(\mathrm{mm})$ & $8.2 \pm 3.5(4.2-19.8)$ & $8.4 \pm 4.3(4.3-23.4)$ & $8.3 \pm 3.9(4.2-23.4)$ \\
Suprailiac skinfold (mm) & $7.8 \pm 5.2(1.0-30.0)$ & $7.8 \pm 4.7(3.1-24.0)$ & $7.8 \pm 4.9(1.0-30.0)$ \\
${ }^{20}$ K (Bq) & $2560 \pm 927(1163-4993)$ & $2624 \pm 1185(1155-5214)$ & $2592 \pm 1058(1155-5214)$ \\
TBK (g) & $83.9 \pm 30.4(38.1-163.7)$ & $85.9 \pm 39.0(37.9-171.0)$ & $84.9 \pm 34.8(37.9-171.1)$ \\
Impedance (ohm) & $612.0 \pm 85.4(427.0-819)$ & $612.1 \pm 99.8(430-820)$ & $612.0 \pm 92.4(427.0-820)$ \\
RI & $39.3 \pm 13.7(19.0-81.8)$ & $39.8 \pm 17.7(17.1-75.1)$ & $39.6 \pm 15.7(17.1-81.8)$ \\
FFM (kg) $\dagger$ & $33.6 \pm 11.1(16.7-61.9)$ & $34.2 \pm 14.1(15.9-64.0)$ & $33.9 \pm 12.6(15.9-64.0)$ \\
\% Fat mass & $20.1 \pm 8.3(1.6-38.2)$ & $19.1 \pm 7.9(3.9-38.4)$ & $19.6 \pm 8.1(1.6-38.4)$ \\
\hline
\end{tabular}

* Data are given as mean $\pm \mathrm{SD}$ (range).

+ Caculated from TBK (13). 
In the first approach to evaluate the predictive value of $\mathrm{BI}$ in combination with other measures of body size, the optimal exponents of impedance, height, weight, or body surface area were estimated using the NLIN procedure of the SAS package (28). The model converged with exponents of -1 for impedance and 2 for height; replacement of height by weight or body surface area or combinations of these did not further reduce the residual variance in the model.

Two approaches were used to express predictive precision and accuracy. The RMSE calculated by linear regression analysis was calculated as the minimum unbiased estimate of the variance, and the $\mathrm{CV}$ was calculated as RMSE divided by mean FFM. In addition, the limits of agreement between the skinfold-derived or the BI-derived FFM estimates and FFM calculated from TBK were estimated by the method of Bland and Altman (29), which allows for methodologic imprecision not only of the method under evaluation but also of the reference technique. Because the size of differences between the FFM values obtained by the different methods tended to be positively related to the size of FFM, analysis was applied to the log-transformed data (29).

To select the model of best fit from the identified predictor variables and other potential contributors, the subjects were randomly assigned to two cross-validation groups. The groups did not differ with regard to sex, age, height, and body composition (Table 1). A stepwise multiple-regression procedure was applied in each group separately to identify the significant independent predictors of FFM. The following variables were offered for selection into the model: height, height ${ }^{2}, 1 /$ impedance, $\mathrm{RI}^{2}$ (height ${ }^{2}$ /impedance), weight, body surface area, age, sex (dummy coded as male $=0$, female $=1$ ), and pubertal status (prepubertal $=0$, pubertal $=1)$. $p$ levels of 0.15 and 0.10 were used for variables to be entered into and to remain in the model during the stepwise regression procedures, respectively.

The stepwise regression procedure was repeated twice, restricting the variables offered to those selected for both validation groups during the previous run. Thus, stable multiple regression equations were developed containing only such predictor variables with significant effect in both validation groups.

To test the equality of the two resulting equations, FFM was calculated in group A according to the equation established in group B and vice versa. The difference between FFM values calculated by each of the two group-specific equations was checked for significance within each group by the $t$ test for dependent variables after verification of normal distributions by the Shapiro-Wilks test.

The same procedure was used to evaluate the significance of the differences between the FFM values obtained by application of the three TBK-derived models $(13,23,24)$ being studied. The applicability of the best-fitting equation to subsets of the population differing in sex, age, or pubertal status was checked by tests of equality of slopes, intercept, or both (30).

\section{RESULTS}

Reliability measurements. The results of the reliability studies are summarized in Table 2. The interobserver $\mathrm{CV}$ of $\mathrm{BI}$ was 4.9 to 11.5 times lower and the intraobserver CV 5.8 to 13.3 times lower than those of the four skinfolds tested. However, neither the intraobserver nor the interobserver CV of FFM, as calculated from the best-fitting equation using the RI and age, differed significantly from those achieved with the skinfold-derived equations.

Estimation of FFM from TBK and conventional anthropometry. The results for FFM as calculated from TBK by use of the equations given by Burmeister (13), Forbes (23), and Lohman (24) are given in Table 3. Use of the Burmeister formula yielded significantly higher estimates of FFM in prepubertal and pubertal children of both sexes than application of the factors suggested by Forbes and Lohman. The FFM estimates according to Forbes
Table 2. Interindividual and intraindividual reliability of anthropometric measurements and derived FFM estimates

\begin{tabular}{|c|c|c|c|c|}
\hline & \multicolumn{2}{|c|}{ Interindividual } & \multicolumn{2}{|c|}{ Intraindividual } \\
\hline & $\begin{array}{l}\text { Technical } \\
\text { error }\end{array}$ & $\begin{array}{l}\mathrm{CV} \\
(\%)\end{array}$ & $\begin{array}{c}\text { Technical } \\
\text { error }\end{array}$ & $\begin{array}{l}\mathrm{CV} \\
(\%)\end{array}$ \\
\hline Height $(\mathrm{mm})$ & 2.8 & 0.17 & 1.5 & 0.10 \\
\hline $\mathrm{BI}(\mathrm{ohm})$ & 9.34 & 1.76 & 3.95 & 0.55 \\
\hline Triceps skinfold (mm) & 1.38 & 8.65 & 0.22 & 3.17 \\
\hline Biceps skinfold $(\mathrm{mm})$ & 2.15 & 20.2 & 0.29 & 7.33 \\
\hline Subscapular skinfold (mm) & 1.78 & 13.3 & 0.22 & 4.24 \\
\hline Suprailiac skinfold (mm) & 1.89 & 15.4 & 0.27 & 5.93 \\
\hline $\begin{array}{l}\text { Upper-arm circumference } \\
(\mathrm{mm})\end{array}$ & 3.70 & 1.34 & 1.10 & 0.60 \\
\hline FFM from RI and age* $(\mathrm{kg})$ & 0.55 & 1.23 & 0.11 & 0.39 \\
\hline $\begin{array}{l}\text { FFM from weight and four } \\
\text { skinfolds } \dagger(\mathrm{kg})\end{array}$ & 0.55 & 1.28 & 0.16 & 0.53 \\
\hline $\begin{array}{l}\text { FFM from weight and two } \\
\text { skinfoldsł }(\mathrm{kg})\end{array}$ & 0.62 & 1.39 & 0.10 & 0.35 \\
\hline
\end{tabular}

* Equation 2.

+ References 18-20.

$\ddagger$ Reference 21 .

were significantly lower than those obtained from the Lohman tables.

The TBK-derived FFM values were also compared with FFM estimates based on measurement of skinfolds and weight by using age-specific formulas based on models that assume either a constant (18-20) or a variable (21) density of the FFM during childhood. The variable density model yielded generally higher FFM estimates than the constant density model $(p<0.001)$. TBK-derived FFM calculated by the Burmeister equation did not differ from the FFM estimate using the constant density model in boys, and differed significantly only in prepubertal girls $(p<0.05)$. The variable density model showed excellent agreement with the Burmeister model in prepubertal boys, but gave moderately higher estimates in prepubertal girls (mean difference $4.1 \%$ ) and pubertal subjects (mean difference $4.5 \%$ in boys, $5.4 \%$ in girls). In contrast, use of the Forbes and Lohman factors resulted in markedly lower estimates of FFM than conventional anthropometry in both prepubertal and pubertal subjects of both sexes (mean within-group differences to variable density model 7.2 to $16.7 \%, p<0.0001$ in all groups).

Estimation of FFM from BI. Variable-exponent regression analysis revealed that the product of height ${ }^{2}$ and impedance ${ }^{-1}$, also referred to as the RI, was the best combination of $\mathrm{BI}$ and a measure of body size to predict FFM. The association between TBK-derived FFM, calculated by the Burmeister equation (13), and the RI is illustrated in Figure 1.

As shown in Table 4, the RI was also more closely correlated with FFM than height ${ }^{2}$ or $1 /$ impedance alone, reducing the RMSE of prediction associated with height ${ }^{2}$ alone by $32.6 \%$. Age, height, weight, and body surface area were weaker although highly significant predictors of FFM. Consequently, we attempted to further improve prediction of FFM by combining RI with these variables and other possible factors of influence such as sex and pubertal status in a multiple linear regression approach, using the cross-validation design outlined above.

Stepwise multiple-regression analysis in the two cross-validation groups yielded the prediction equations given in Table 5. $\mathrm{RI}$, age, and weight were identified as significant independent predictors of FFM in both groups. Multiple regression was repeated in both groups, offering only these three variables for inclusion into the model. The second step of deduction showed a significant effect of RI and age in both groups, whereas the effect of weight was significant only in group B. Therefore, the following prediction equations were established in both groups using only RI and age as independent predictor variables (coefficients \pm SEM): 
Table 3. Estimated FFM based on measurements of TBK using different conversion factors and according to conventional anthropometry using either constant or variable FFM density models*

\begin{tabular}{|c|c|c|c|c|}
\hline & \multicolumn{4}{|c|}{ FFM (kg) } \\
\hline & \multicolumn{2}{|c|}{ Boys } & \multicolumn{2}{|c|}{ Girls } \\
\hline & Prepubertal & Pubertal & Prepubertal & Pubertal \\
\hline TBK-Burmeister equation (13) & $24.6 \pm 4.5^{\mathrm{hc}}$ & $46.2 \pm 11.3^{\text {hie }}$ & $24.0 \pm 4.0^{\text {txde }}$ & $36.6 \pm 5.8^{\text {trec }}$ \\
\hline TBK-Forbes equations (23) & $22.6 \pm 4.5^{\mathrm{acde}}$ & $44.8 \pm 12.1^{\text {acde }}$ & $21.5 \pm 4.2^{\mathrm{acde}}$ & $34.9 \pm 6.5^{\text {acde }}$ \\
\hline TBK-Lohman tables (24) & $23.1 \pm 4.4^{\text {ahde }}$ & $44.3 \pm 11.3^{\text {ahde }}$ & $23.0 \pm 4.4^{\text {abde }}$ & $36.0 \pm 6.1^{\text {acde }}$ \\
\hline Skinfolds-constant density $(18-20)$ & $24.1 \pm 4.1^{\text {hee }}$ & $47.1 \pm 11.8^{\text {tree }}$ & $25.0 \pm 4.7^{\mathrm{abc}}$ & $37.3 \pm 6.9^{\text {bic }}$ \\
\hline Skinfolds-variable density (21) & $24.8 \pm 4.3^{\text {hxd }}$ & $48.1 \pm 11.7^{\text {atred }}$ & $25.1 \pm 4.8^{\mathrm{abc}}$ & $38.6 \pm 6.9^{\text {athed }}$ \\
\hline
\end{tabular}

* Data are given as mean \pm SD. Numbers in parentheses are reference numbers. Superscript letters denote significant difference from FFM derived from TBK according to Burmeister (a), Forbes (b), and Lohman (c), and from FFM estimated from skinfold measurements according to constant (d) and variable (e) FFM density models.

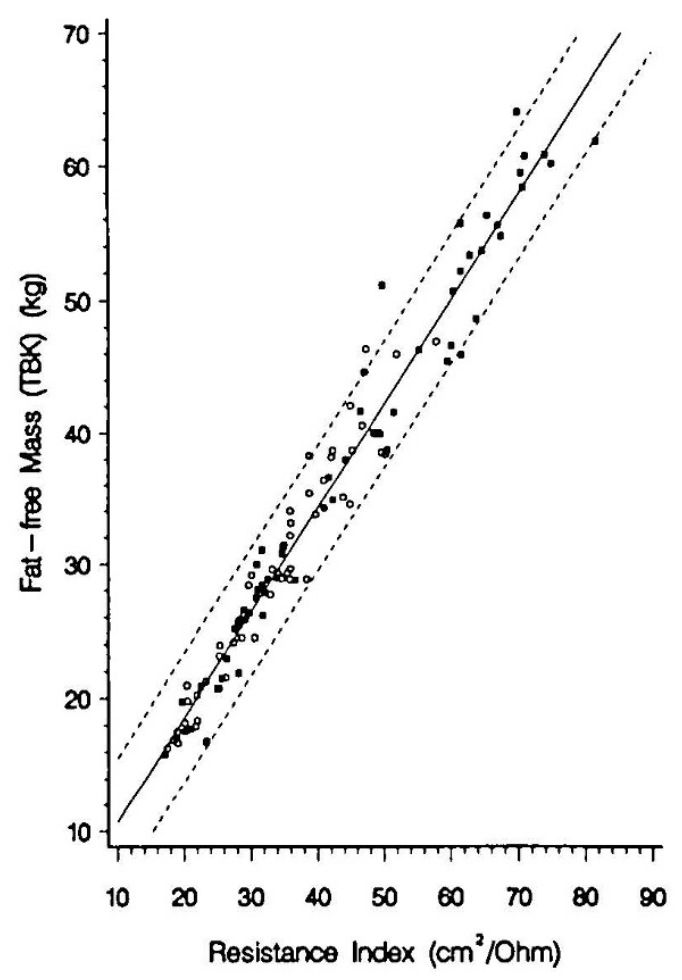

Fig. 1. Association between RI and TBK-derived FFM in 112 healthy children. Male subjects are represented by filled squares, female subjects by open circles. Lines indicate regression line and $95 \%$ prediction intervals for individual measurements.

Table 4. Stepwise multiple regression analysis in the two crossvalidation subgroups

\begin{tabular}{|c|c|c|c|}
\hline & Model $R^{2}$ & $F$ & $p$ \\
\hline \multicolumn{4}{|l|}{ Group A } \\
\hline RI & 0.940 & 840 & 0.0001 \\
\hline Age & 0.964 & 35.7 & 0.0001 \\
\hline Sex & 0.966 & 3.75 & 0.0581 \\
\hline $1 /$ Impedance & 0.970 & 5.35 & 0.0247 \\
\hline Weight & 0.971 & 3.26 & 0.0769 \\
\hline \multicolumn{4}{|l|}{ Group B } \\
\hline RI & 0.980 & 2519 & 0.0001 \\
\hline Weight & 0.985 & 17.0 & 0.0001 \\
\hline Age & 0.987 & 7.0 & 0.0108 \\
\hline Height & 0.988 & 5.4 & 0.0243 \\
\hline Pubertal status & 0.989 & 3.1 & 0.0826 \\
\hline
\end{tabular}

Table 5. Regression analyses of various anthropometric variables with TBK-derived FFM

\begin{tabular}{|c|c|c|c|c|}
\hline $\begin{array}{l}\text { TBK-derived } \\
\text { FFM vs: }\end{array}$ & $R^{2}$ & $\begin{array}{c}\text { RMSE } \\
(\mathrm{kg})\end{array}$ & $\begin{array}{l}\text { CV } \\
(\%)\end{array}$ & Equation \\
\hline RI & 0.964 & 2.40 & 7.1 & $\mathrm{FFM}=0.79 \cdot \mathrm{RI}+2.84$ \\
\hline $\begin{array}{l}\text { Body surface } \\
\text { area }\end{array}$ & 0.934 & 3.24 & 9.6 & $F F M=35.4 \cdot B S A-13.4$ \\
\hline Height $^{2}$ & 0.920 & 3.56 & 10.5 & $\mathrm{FFM}=0.002 \cdot \mathrm{ht}^{2}+13.4$ \\
\hline Weight & 0.913 & 3.71 & 10.9 & $\mathrm{FFM}=0.73 \cdot \mathrm{wt}+2.85$ \\
\hline Height & 0.896 & 4.07 & 12.0 & $F F M=0.60 \cdot h t-56.8$ \\
\hline Age & 0.787 & 5.81 & 17.2 & $\mathrm{FFM}=3.01 \cdot$ age -1.77 \\
\hline
\end{tabular}

Group 1: FFM $=0.22( \pm 0.97)+0.62( \pm 0.03)$

$\cdot \mathrm{RI}+0.76( \pm 0.13) \cdot$ age

Group 2: FFM $=0.45( \pm 0.90)+0.68( \pm 0.03)$

$\cdot \mathrm{RI}+0.58( \pm 0.16) \cdot$ age

Model $R^{2}$ was 0.964 (RMSE, $2.13 \mathrm{~kg} ; \mathrm{CV}, 6.3 \%$ ) and 0.984 (RMSE, $1.83 \mathrm{~kg} ; \mathrm{CV}, 5.4 \%$ ) for equations $1 \mathrm{a}$ and $\mathrm{lb}$, respectively.

The confidence intervals of the regression coefficients showed large overlap between the two equations. Cross validation of the prediction equations by crossover application of the group-specific equations and comparison of the FFM values calculated by the two equations yielded no significant differences in either group. Therefore, data from group A and B were combined to give a common prediction model based on RI and age:

$F F M=0.15( \pm 0.64)+0.65( \pm 0.02) \cdot R I+0.68( \pm 0.10) \cdot$ age

The inclusion of age in the prediction equation reduced the RMSE by $18 \%$ to $1.98 \mathrm{~kg}$ or $5.8 \%$.

The size of the residual difference between FFM estimated by cquation 2 and FFM calculated from TBK was proportional to the mean size of FFM. Therefore, the calculated $95 \%$ confidence interval for an individual FFM measurement $(2 \cdot \mathrm{RMSE}=3.88$ $\mathrm{kg}$ ) is an overestimate in the lower range and an underestimate in the upper range of FFM (Fig. 1). As illustrated in Figure 2, $\log$ transformation of the differences between BI-derived and TBK-derived FFM values eliminated this proportionality. Analysis of the log-transformed data revealed that for $95 \%$ of the cases an FFM estimate based on equation 2 would lie between $11.1 \%$ below and $12.4 \%$ above the FFM value calculated from TBK.

To test whether the best-fit prediction equation derived from the total sample was equally valid for both sexes and in different age groups, homogeneity of slopes and intercepts for the regression between measured and estimated FFM was evaluated for the following subgroup comparisons: 1 ) boys versus girls; and 2) age $<10.0$ y versus age 10.0 to 14.0 y versus age $>14.0 \mathrm{y}$. Explained variance was slightly worse in girls $\left(R^{2}=0.951, \mathrm{RMSE}\right.$ $=1.99 \mathrm{~kg}, \mathrm{CV}=6.4 \%)$ than in boys $\left(R^{2}=0.982, \mathrm{RMSE}=1.94\right.$ 


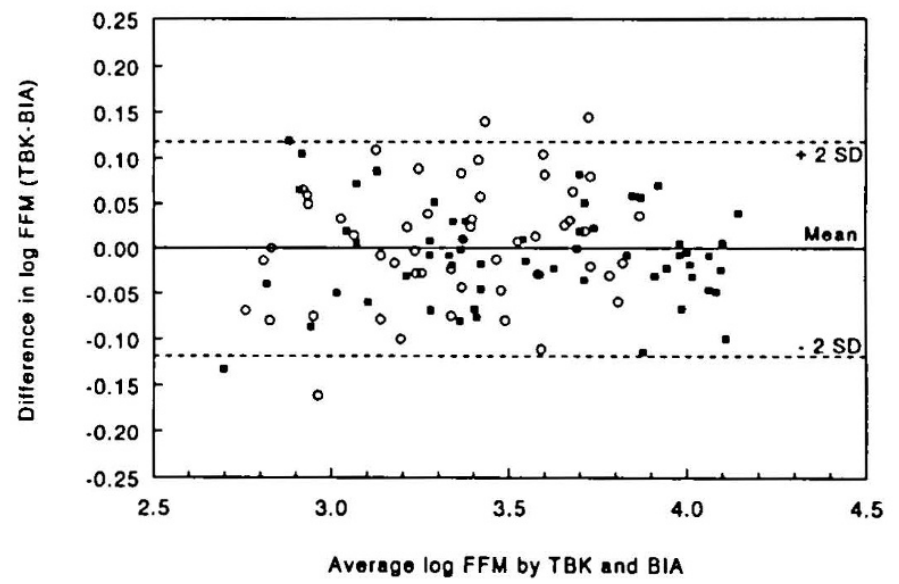

Fig. 2. Distribution of differences between log-transformed values of FFM estimated according to equation 2 [FFM $\mathrm{Bl}$ analysis (BLA)] and FFM calculated from TBK in relation to the mean (log-transformed) value of FFM calculated by both methods. Male subjects are represented by filled squares, female subjects by open circles. The dashed lines indicate the $95 \%$ limits of agreement for a single measurement.

$\mathrm{kg}, \mathrm{CV}=5.2 \%$ ), with no significant difference in slopes or intercepts. No differences in explained variance were found between the age groups ( $<10 \mathrm{y}: R^{2}=0.901, \mathrm{RMSE}=1.45 \mathrm{~kg}$, $\mathrm{CV}=6.5 \% ; 10-14 \mathrm{y}: R^{2}=0.900, \mathrm{RMSE}=1.72 \mathrm{~kg}, \mathrm{CV}=5.3 \%$; $>14$ y: $R^{2}=0.913, \mathrm{RMSE}=2.49 \mathrm{~kg}, \mathrm{CV}=5.0 \%$ ). However, significant variation was found among the age groups $(p<0.01)$; the slope of the regression line in the 10- to 14-y-old children differed from that of the other two groups.

Table 6 lists the results from regression analyses between predicted FFM using various formulas incorporating RI established in previous studies in children and FFM as measured by ${ }^{40} \mathrm{~K}$ spectrometry. Explained variance was high with all prediction equations, with $\mathrm{CV}$ between 5.3 and $8.5 \%$. The formulas given by Deurenberg et al. (7) combining RI with height, weight, and sex yielded the same predictive precision as the equation developed in the present analysis. The Deurenberg formulas tended to underpredict FFM in children with less than $33 \mathrm{~kg}$ of FFM and overpredict FFM in those with more than $33 \mathrm{~kg}$ of FFM, with mean differences of $-10 \%$ at the low end and $+5.2 \%$ at the high end of the range of FFM studied. The equation based on RI and weight given by Houtkooper et al. (4) systematically overpredicted FFM by an average of $5.8 \%$. The formula derived by Cordain et al. (5) in a smaller number of 9- to 14-y-old subjects based on RI alone overpredicted FFM by an average of $14.5 \%$. The equations validated in children using $\mathrm{H}_{2}{ }^{18} \mathrm{O}$ dilution $(31,32)$ were used to predict FFM by dividing estimated total body water by 0.73 . Applied in this way, the equations systematically underpredicted FFM by a mean of $6 \%$ (31) and $8.8 \%$ (32), respectively.

Estimation of FFM from skinfold measurements. The predictive precision of FFM estimates obtained by conventional anthropometry (weight, skinfolds) based on either constant or variable FFM density models was comparable with that of the BI-derived best-fitting equations developed in this and other studies (Table 6). Both models systematically overpredicted true FFM. The mean difference between observed and predicted FFM was $0.55 \mathrm{~kg}(1.6 \%)$ for the constant-density model and $1.49 \mathrm{~kg}$ $(4.5 \%)$ for the variable-density model. The calculated $95 \%$ limits of agreement (29) for FFM estimates based on the variabledensity model were $7.9 \%$ below and $17.3 \%$ above the TBKderived FFM.

\section{DISCUSSION}

The present study was designed to delineate the usefulness of the BI technique in the assessment of body composition in a large group of children as young as $4 \mathrm{y}$ old. The most immediate advantage of the use of $\mathrm{BI}$ in younger children is the good acceptance of the measurements, particularly when used repeatedly, whereas skinfold measurements are sometimes perceived as uncomfortable or even painful.

We observed an excellent intraobserver and interobserver reproducibility of $\mathrm{BI}$, which was far better than achieved with skinfold measurements. However, when the measurement errors were included in BI-specific and skinfold-specific predicting equations of FFM, the laws of error transmission resulted in similar derived technical errors for FFM estimates based either on the RI or on conventional anthropometry. Thus, the practical advantage gained from the high technical precision of $\mathrm{BI}$ is probably small, at least in children within the normal range of body composition. Of course, our observations relate to a singlelaboratory setting with two trained observers performing all measurements; BI analysis may retain some advantage over conventional anthropometry in studies involving multiple observers with different levels of technical experience, where the

Table 6. Predictive accuracy and precision of FFM estimates obtained by use of various BI-derived or skinfold-derived equations from literature in the present sample of 112 healthy children*

\begin{tabular}{|c|c|c|c|c|c|c|c|}
\hline & Validation method & $R^{2}$ & $\begin{array}{l}\text { RMSE } \\
(\mathrm{kg})\end{array}$ & $\begin{array}{l}\mathrm{CV} \\
(\%)\end{array}$ & $\begin{array}{l}\text { Slope } \\
\pm \text { SEM }\end{array}$ & $\begin{array}{l}\text { Intercept } \\
\pm \text { SEM }\end{array}$ & $\begin{array}{c}\text { Difference predicted- } \\
\text { observed } \\
\text { (mean } \pm \text { SEM }) \\
(\mathrm{kg})\end{array}$ \\
\hline \multicolumn{8}{|l|}{ BI-derived FFM equations } \\
\hline Present study & ${ }^{41} \mathrm{~K}$ & 0.975 & 1.98 & 5.8 & $1.00 \pm 0.01$ & $0.1 \pm 0.5$ & $0.0 \pm 0.2 \dagger$ \\
\hline Deurenberg $c t$ al. (7) & Densitometry & 0.975 & 1.98 & 5.8 & $0.88 \pm 0.01$ & $3.7 \pm 0.4$ & $0.2 \pm 0.3 \dagger$ \\
\hline Houtkooper et al. (4) & Densitometry/ $\mathrm{D}_{2} \mathrm{O}$ & 0.973 & 2.07 & 6.1 & $0.96 \pm 0.01$ & $-0.6 \pm 0.6$ & $2.0 \pm 0.2 \ddagger$ \\
\hline Cordain et al. (5) & Densitometry & 0.964 & 2.40 & 7.1 & $0.97 \pm 0.02$ & $-3.8 \pm 0.7$ & $5.0 \pm 0.2 \ddagger$ \\
\hline Davies et al. (31) & $\mathrm{H}_{2}{ }^{1 \times} \mathrm{O}$ & 0.964 & 2.40 & 7.1 & $0.96 \pm 0.02$ & $3.5 \pm 0.6$ & $-2.1 \pm 0.2 \ddagger$ \\
\hline Gregory et al. (32) & $\mathrm{H}_{2}{ }^{18} \mathrm{O}$ & 0.964 & 2.40 & 7.1 & $1.04 \pm 0.02$ & $1.7 \pm 0.6$ & $-3.0 \pm 0.2 \ddagger$ \\
\hline \multicolumn{8}{|l|}{$\begin{array}{l}\text { Skinfold-derived FFM equa- } \\
\text { tions }\end{array}$} \\
\hline $\begin{array}{l}\text { Constant FFM density model } \\
(18-20)\end{array}$ & $\mathrm{D}_{2} \mathrm{O} /$ densitometry & 0.975 & 1.95 & 5.8 & $0.95 \pm 0.01$ & $1.2 \pm 0.5$ & $0.6 \pm 0.2 \S$ \\
\hline $\begin{array}{l}\text { Variable FFM density model } \\
\text { (21) }\end{array}$ & $\mathrm{D}_{2} \mathrm{O} /$ densitometry & 0.973 & 2.06 & 6.1 & $0.93 \pm 0.02$ & $1.0 \pm 0.6$ & $1.5 \pm 0.2 \S$ \\
\hline
\end{tabular}

* FFM as calculated from TBK was used as reference standard.

$\dagger$ Not significantly different from 0 .

$\ddagger$ Different from 0 at $p<0.0001$.

$\S$ Different from 0 at $p<0.01$. 
difference in measurement precision between BI and conventional anthropometry may be even greater.

We applied ${ }^{40} \mathrm{~K}$ spectrometry as a reference technique to measure true FFM. This method has the advantage of being applicable even in young children (15) and avoids some methodologic limitations inherent to the densitometry and isotope dilution techniques. However, there has been some confusion regarding the factors that should be used in children to convert TBK to FFM.

Forbes (23) on the basis of direct chemical analysis of four adult cadavers and the concept of chemical maturity of the growing body beyond early infancy, claimed that the potassium content of boys was constantly $68.1 \mathrm{mmol} / \mathrm{kg}(2.66 \mathrm{~g} / \mathrm{kg}) \mathrm{FFM}$ and that the potassium content of girls would decrease during puberty from 68.1 to $64.3 \mathrm{mmol} / \mathrm{kg}(2.51 \mathrm{~g} / \mathrm{kg})(23)$. Fomon et al. (25) and Haschke (26) challenged the concept of "chemical maturity" by combining isotope dilution, TBK, and total body calcium data from different literature sources to deduce changes in body composition of the reference child throughout childhood. They postulated that the density of the FFM gradually increased during childhood. Lohman (24) constructed a table of agespecific TBK-FFM conversion factors based on the data composed by Fomon et al. and Haschke that showed a gradual increase of potassium concentration in the FFM from 49.1 $\mathrm{mmol} / \mathrm{kg}(1.92 \mathrm{~g} / \mathrm{kg}) \mathrm{FFM}$ in the infant to $70.6 \mathrm{mmol} / \mathrm{kg}(2.76$ $\mathrm{g} / \mathrm{kg})$ in the young adult male and $64.5 \mathrm{mmol} / \mathrm{kg}(2.52 \mathrm{~g} / \mathrm{kg})$ in the young adult female. However, the conversion factors calculated by Fomon et al. and Haschke may still overestimate the potassium contents of the FFM in childhood; when relating measured TBK values to FFM determined densitometrically using the age-specific FFM density constant suggested by the multiple-component model of Lohman (24), Cordain et al. (33) estimated a value of $58.9 \mathrm{mEq}$ of potassium $/ \mathrm{kg} \mathrm{FFM} \mathrm{in} 10-$ to 14-y-old boys, whereas from Haschke's data an average value of $67.8 \mathrm{mmol} / \mathrm{kg}$ was calculated for this age group (26).

Several lines of evidence suggest that the apparent increase in the TBK:FFM ratio during childhood is related to two factors: first, a relative decrease in extracellular volume and increase in intracellular volume occurs during childhood $(10,34)$; and second, the relative proportions of muscle, skin, and skeleton, all of which have different specific potassium contents, vary across childhood (10). Burmeister (13) has offered an intuitive solution to the problem of changing TBK:FFM ratios in childhood. Using a three-compartment model of FFM (body cell mass, extracellular solids, and extracellular fluid), he proposed a constant potassium concentration of $92.5 \mathrm{mEq} / \mathrm{kg}$ in the body cell mass, a value validated by relating body cell mass, derived from measured or estimated body fluid spaces, to TBK in large numbers of children aged 6-20 y (35). Extracellular fluid space, determined as thiosulfate space, was found to be closely correlated with body surface area (22). Simplifying the three-compartment model by assuming that extracellular solids account for a constant $10 \%$ fraction of body cell mass, FFM becomes a linear function of TBK and body surface area. Because the increase of TBK is proportionately greater than that of body surface area during childhood, the contribution of body surface area, reflecting extracellular fluid, will gradually decrease and TBK:FFM ratios increase during childhood. Entering empirical mean values for height, weight, and TBK into this model yielded TBK:FFM ratios precisely matching those found by direct chemical analysis in cadaver dissection studies of both neonates and adults (36, 37). In addition, Oberhausen et al. (35), using the Burmeister model, calculated the potassium:FFM ratio of an average 10-yold boy to be $59.6 \mathrm{mEq} / \mathrm{kg}$, a value similar to the one estimated by Cordain et al. (33) when relating TBK to FFM measured densitometrically. Thus, although some bias may arise during puberty, when the increase of bone mineral content is more pronounced than that of body cell mass, this model may provide a sufficiently accurate description of the relationship between TBK and FFM during most parts of childhood.
As expected, markedly lower values were calculated for FFM in this study when the conversion factors given by Forbes (23) or Lohman (24), based on the work of Fomon et al. (25) and Haschke (26), were used than with the Burmeister model. In addition to the different handling of the concept of chemical maturation outlined above, the discrepant estimates of FFM obtained with the different TBK-derived calculations of FFM may be partly related to the use of different types of ${ }^{40} \mathrm{~K}$ counters in the validating studies $(35,38,39)$.

Prediction equations of FFM from weight and skinfold measurements based on either constant (18-20) or variable (21) FFM density models, although showing markedly higher FFM estimates in comparison with TBK-derived FFM using the Forbes or Lohman conversion factors, yielded similar or slightly higher values of FFM than estimated by the Burmeister model. The difference between FFM according to the variable-density model and FFM calculated according to the Burmeister model reached significance in girls and in pubertal subjects, which may be related to the fact that the latter model does not account for sexspecific or maturational differences in the relative proportion or specific density of skin, muscle, or bone. However, the variable FFM density model applied here is also based on a number of assumptions. In the absence of human data on the chemical composition of FFM, both models must be regarded as hypothetical, and it cannot be decided whether the variable-density model slightly overestimates or the Burmeister model underestimates FFM. Nonetheless, in terms of greatest intermethodologic concordance, the Burmeister model of calculating FFM from TBK seems to be the most appropriate of the different pediatric TBK-FFM conversion systems available.

Variable-exponent curve fitting revealed that the product of height $^{2}$ and impedance ${ }^{-1}$ was the combination of $\mathrm{BI}$ with a measure of body size that was most closely correlated with FFM as determined from TBK. This finding confirms the results obtained by Houtkooper et al. (4), who validated BI by use of densitometry, indicating that the term height ${ }^{2} /$ impedance, or RI, is of general validity in predicting FFM, independent of the method of validation used.

Our approach to deriving a best-fitting predictive model of FFM from combinations of RI with other anthropometric parameters and subject characteristics was directed not only at finding the subset of variables explaining most of the variance in the predicted variable but also at avoiding the problem of overspecificity. Among the several mathematical options available, the use of two cross-validation groups and stepwise elimination of those variables that did not appear to be of significant effect in both groups seemed to be a sufficiently stringent way of deriving a generalizable pediatric equation.

Apart from RI, age emerged as the only predictor variable with a consistent independent effect on FFM. This observation confirms the findings of Deurenberg et al. $(6,7)$, who hypothesized that the relative increase of the intracellular compartment, which has a higher specific resistance to electrical current (40), during childhood results in an increase in whole-body impedance with age at a given FFM and height during childhood. In the population studied here, this maturational factor was better expressed by age than height or weight. However, the additional predictive precision contributed by any of these variables is probably small. Using the best-fitting equations given by Houtkooper et al. (4) (RI, weight) and Deurenberg et al. (7) (RI, weight, height, gender) to predict FFM in the present sample, we achieved $R^{2}$ values similar to those obtained with the equation derived in this study. Deurenberg $e t$ al. (7) noted a small independent predictive effect of gender. Although this variable was not included during the model selection process and the slopes of the regression lines for the two sexes did not differ significantly, the $R^{2}$ achieved with the common best-fitting equation was lower in girls $(0.95)$ than in boys (0.98). This may be because of a slight deviation from linearity in the association between FFM and RI in the girls, 
possibly related to specific changes of female body composition during puberty.

Our external validation of prediction equations published previously showed an excellent predictive precision for the formulas given by Deurenberg et al. (7) and Houtkooper et al. (4), and good predictive accuracy at least for the Deurenberg formula. The systematic overestimation of true FFM in the studies of Houtkooper et al. may be related to the fact that only 10- to 14$y$-old children were studied. This age range may have been too limited to sufficiently allow for the age dependency of the relationship between RI and FFM during childhood, which may have resulted in biased estimates, particularly at the low end of the range of FFM studied. In those studies where total body water, measured by $\mathrm{H}_{2}{ }^{18} \mathrm{O}$ isotope dilution, had been predicted from RI $(31,32)$, TBK-derived FFM was systematically underpredicted. Inasmuch as it has been suggested that the hydration of FFM is not, as assumed in our calculations, constant throughout childhood but rather decreases from a higher level to the adult value of $73 \%(11,24)$, FFM would have been underestimated even more markedly if age-specific TBW-FFM conversion factors had been used. Most likely, the profound underestimation of FFM observed with these formulas is caused by their validation in diseased subjects, including patients with growth hormone deficiency, chronic gastrointestinal disease, and diabetes. All these disorders are known to be associated with abnormalities of body composition, including alterations of the mineral distribution between fluid compartments (34). Our results underscore that prediction equations validated in children with abnormal body composition are not applicable to normal children and that specific formulas need to be derived to predict body composition from $\mathrm{Bl}$ in children with particular diseases.

Although we observed a very close association between the RI and the FFM calculated from TBK, it should be stressed that the limits of agreement for individual measurements of FFM according to the derived FFM are wide: $95 \%$ of individual FFM estimates would lie within a range not narrower than $23 \%$ of the true FFM. This measurement uncertainty was virtually identical with that found for FFM estimates based on conventional skinfold measurements. Part of this rather poor predictability may be related to the method of reference, given a technical error with ${ }^{41} \mathrm{~K}$ counting of $3.5^{\circ} \%$ and the potential inaccuracies of FFM calculation inherent to the changing TBK:FFM ratio during childhood. Moreover, $\mathrm{BI}$ measurements at $50 \mathrm{kHz}$ largely reflect the resistance offered by the arms and legs and the contribution of the extracellular fluid volume, inasmuch as the cell membrane capacitive effects are maximal at this frequency. Thus, whereas ${ }^{40} \mathrm{~K}$ counting primarily provides a measure of body cell mass, $\mathrm{BI}$ measurements may be a better reflection of total body water. Part of the residual variability may be related to variations in the contribution of body cell mass and body water to true FFM. On the other hand, the relationship between $\mathrm{BI}$ and total body water observed in other studies $(31,32)$ was not any closer than that between $\mathrm{BI}$ and TBK-derived FFM studied herein.

In summary, our study demonstrates that BI analysis has precision and accuracy similar but not superior to conventional skinfold anthropometry in assessing FFM in children, at least when both techniques are applied by trained anthropometrists and when only the normal range of body composition is considered. Future research will have to evaluate whether BI offers advantages over conventional anthropometry in studies involving multiple observers and children with abnormal body composition.

Acknouledgments. The authors thank Ina Kattwinkel, Uta Mohr, and Elke Wühl for help with the measurements; Rotraut Schulte and Babette Hake for helpful discussion of data analysis; and Drs. M. Kieser and R. Holle for valuable statistical advice.

\section{REFERENCES}

1. Segal K. Gutin B. Presta E. Wang J. van Itallie T 1985 Estimation of human body composition by electrical impedance methods: a comparative study. J Appl Physiol 58:1565-1571

2. Lukaski H. Bolonchuk W, Hall C. Siders W 1986 Validation of tetrapolar bioelectrical impedance method to assess human body composition. J Appl Physiol 60:1327-1332

3. Jackson AS, Pollock ML. Graves JE. Mahar MT 1988 Reliability and validity of bioelectrical impedance in determining body composition. J Appl Physiol 64:529-534

4. Houtkooper LB, Lohman TG, Going SB, Hall MC 1989 Validity of bioelectrical impedance for body composition assessment in children.J Appl Physiol $66: 814-821$

5. Cordain L. Whicker RE, Johnson JE 1988 Body composition determination in children using bioelectrical impedance. Growth Dev Aging 52:37-40)

6. Deurenberg P. Kusters CSL. Smit HE 1990 Assessment of body composition by bioelectrical impedance is strongly age-dependent. Eur J Clin Nutr 44:261-268

7. Deurenterg P, van der Kooy K. Leenen R. Weststrate JA. Scidell JC 1991 Sex and age specific prediction formulas for estimating body composition from bioelectrical impedance: a cross-validation study. Int J Ohesity 15:17-25

8. Guo S. Roche AF. Houthooper L 1989 Fat-free mass in children and young adults predicted from bioelectric impedance and anthropometric variables. Am J Clin Nutr 50:435-443

9. Bradbury MWB 1961 Urea and deuterium-oxide spaces in man. Br J Nutr 15:177

10. Widdowson EM 1974 Changes in body proportions and composition during growth. In: Davis JA. Dobbing J (eds) Scientific Foundations of Pediatrics. William Heinemann Medical Books Ltd, London, pp 153-163

11. Boileau R, Lohman T, Slaughter M, Ball T, Going S, Hendrix M 1984 Hydration of the fat-free body in children during maturation. Hum Biol 56:651-666

12. Pierson RN, Lin DH 1972 Measurement of hody compartments in children: whole-body counting and other methods. Semin Nucl Med 2:373-382

13. Burmeister $W 1965$ Potassium- 40 content as a basis for the calculation of body cell mass in man. Science 148:1336-1337

14. Burmeister W. Fromberg (; 1970) Depotfett, hestimnt nach der Kalium-40Methode, und seine Besichung lur l lautfaltendiche bei $4-19$ jahrigen. Arch Kinderheilkunde 180:228-238

15. Burmeister W, Romahn A. Kunkel R 1970 Die Entwicklung des KaliumBestandes von 19 einheitlich ernahrten Säuglingen. Arch Kinderheilkunde 180:218-227

16. Cameron N 1984 The Measurement of Human Growth. Croom Helm Lid, London

17. Tanner JM 1962 Growth at Adolescence, 2nd Ed. Blackwell Scientific Publications, Oxford, UK

18. Brook CGD 1971 Determination of body composition of children from skinfold measurements. Arch Dis Child 46:182-184

19. Durnin JVGA, Rahaman MM 1967 The assessment of the amount of fat in the human body from measurements of skinfold thickness. Br J Nutr 21:681689

20. Durnin JVGA. Womersley J 1974 Body fat assessed from total body density and its estimation from skinfold thickness: measurements on 481 men and women aged from 16 to 72 years. Br J Nutr 32:77-97

21. Slaughter MH, Lohman TG, Boileau RA. Horswill CA. Stillman RJ, van Loan MD, Bemben DA 1988 Skinfold equations for estimation of body fatness in children and youth. Hum Biol 60:709-723

22. Burmeister W 1961 Der Extracellular-(Thiosulfat)-raum im menschlichen Organismus während des Wachstums. Ann Univ Saraviensis Med 9:167219

23. Forbes GB 1986 Body composition in adolescence. In: Falkner F. Tanner JM (eds) Human Growth, Vol II. Blackwell Scientific Publications. Oxford, UK pp 119-145

24. Lohman TG 1986 Applicability of body composition techniques and constants for children and youths. In: Pandolph KB (ed) Exercise and Sport Science Reviews. Macmillan. New York. pn 325-357

25. Fomon SJ, Haschke F, Ziegler EE. Nelson SE 1982 Body composition of reference children from birth to age 10 years. Am J Clin Nutr 35:1169-1175

26. Haschke F 1983 Body composition of the adolescent matc. Acta Paediatr Scand Suppl 3()7:1-23

27. Lukaski HC. Johnson PE. Bolonchuk WW. Lykken CII 1985 Assessment of fat-free mass using bioelectrical impedance measurements of the human body. Am J Clin Nutr 41:810-817

28. SAS Institute Inc 1988 SAS/STAT User`s Guide. Release 6.03 Edition. SAS Institute, Cary, NC

29. Bland JM, Altman DG 1986 Statistical methods for assessing agreement between two methods of clinical measurement. Lancet 1:307-310

30. BMDP Statistical Software 1983 BMDP Statistical Software Manual: Multiple linear Regression. University of California Press, Berkeley, CA, pp 237-249

31. Davies PSW, Preece MA. Hicks CJ, Halliday D 1987 The prediction of total 
body water using bioelectrical impedance in children and adolescents. Ann Hum Biol 15:237-240

32. Gregory JW, Greene SA, Scrimgeour CM, Rennie MJ 1991 Body water measurement in growth disorders: a comparison of bioclectrical impedance and skinfold thickness techniques with isotope dilution. Arch Dis Child 66:220-222

33. Cordain L, Johnson JE, Bainbridge CN, Wicker RE, Stockler JM 1989 Potassium content of the fat free body in children. J Sport Med Phys Fit 29:170176

34. Forbes G 1987 Human Body Composition. Springer-Verlag. New York

35. Oberhausen E, Burmeister W, Huycke EJ 1965 Das Wachstum des Kaliumbestandes im Menschen gemessen mit dem Ganzkörperzähler. Ann Paediatr 205:381-400
36. Widdowson EM 1950 Chemical composition of newly born mammals. Nature 166:626-628

37. Forbes G, Gallup J, Hursh JB 1961 Estimation of total body fat from potassium-40 content. Science 133:101-102

38. Forbes GB, Schultz F, Cafarelli C, Amishakimi GH 1968 Effects of body size on potassium-40 measurement in the whole body counter (tilt-chair technique). Health Phys 15:435-442

39. Romahn A, Burmeister W 1970 Gesamtkaliumbestimmungen bei Säuglingen und Kleinkindern mit einem Babycounter. Arch Kinderheilk 180:239-248

40. Deurenberg P, van der Kooy K, Leenen R, Schouten FJM 1989 Body impedance is largely dependent on the intra- and extracellular water distribution. Eur J Clin Nutr 43:845-853 